\title{
Association Between Costochondritis and Vitamin D Deficiency: An Observational Study
}

Dr Mahendra Chourasiya ${ }^{1}$, Dr Abhishek Rathore ${ }^{2}$, Dr Indu Bhana ${ }^{3}$

${ }^{1}$ DM Cardiology, Assistant Professor, Cardiology, Department of Cardiology, Mahatma Gandhi Memorial Medical College Indore, Madhya Pradesh, India

${ }^{2}$ DM Cardiology, Assistant professor, Department of Cardiology, Super-Speciality, Mahatma Gandhi Memorial Medical College Indore, Madhya Pradesh, India

${ }^{3}$ DM Neurology, Consultant neurology, Vishesh Jupitor Hospital, Indore, Madhya Pradesh, India

Article Info: Received 10 September 2021; Accepted 29 October 2021

DOI: https://doi.org/10.32553/jbpr.v10i6.887

Corresponding author: Dr Mahendra Chourasiya

Conflict of interest statement: No conflict of interest

\begin{abstract}
Background: Vitamin D is an integral part of bony health. Its deficiency leads to multiple bony pains, including costochondritis.

Aims and Objectives: Present study aimed to evaluate the association of costochondritis with vitamin D deficiency.

Materials and Methods: A total of 100 patients with chest pain with costochondral tenderness were taken. Clinical history, examination, investigation, including electrocardiogram, echocardiogram, and chest $\mathrm{x}$-ray was made.

Results: $63 \%$ and $37 \%$ were female and male, respectively. Mean vitamin D level was low in females as compared to males (21.9 \pm 8.47 and $31.7 \pm 6.23$ respectively). Prolonged duration of chest pain was associated with low vitamin D level that was statistically significant $(\mathrm{p}<0.001)$.

Conclusion: Vitamin D deficiency is common in the Indian community, may lead to bony pains, costochondritis, osteomalacia. Replacement of vitamin D is recommended to alleviate skeletal manifestations.
\end{abstract}

Keywords: vitamin D deficiency, non-cardiac chest pain, costochondritis

\section{Introduction}

Chest pain is one of the common causes of presentation in cardiology clinics and the emergency room. More than 6 million emergency room visits in the United States [1]. Most chest pain patients are discharged as musculoskeletal causes of chest pain, including costochondritis [2, 3]. The etiology of costochondritis is unclear but may be related to viral fever, other inflammatory conditions, trauma or vitamin D deficiency, and osteomalacia [3]. In India, vitamin D deficiency is widespread in all age groups due to poor nutritional status and lack of sun exposure [4]. There is no standard guideline followed worldwide for classifying the Vitamin D status; studies had different cutoff values for the deficiency. Most of these studies used serum $25(\mathrm{OH})$ D level of $<20 \mathrm{ng} / \mathrm{ml}$ as Vitamin D deficiency. A lack of studies about the 
association between vitamin D deficiency and costochondritis, particularly in the Indian population [4-6], in a present study aimed to evaluate the association between vitamin D deficiency and costochondritis.

\section{Material and methods:}

The present study was conducted in MY hospital and MGM medical college, Indore (Madhya Pradesh), from June 2020 to June 2021. One hundred patients were included in the study, those who presented with non-cardiac pain (costochondral tenderness) in the cardiology clinic.

Inclusion criteria: Patients with non-cardiac pain who have costochondral tenderness with normal electrocardiogram were included in the study.

Exclusion criteria: Patients with cardiac pain, pulmonary etiology, gastrointestinal etiology were excluded. Similarly with abnormal electrocardiograms and echocardiograms, and established cardiac disease were excluded from the study.

Study procedure: All patients were examined as per protocol, including clinical history and examination. Electrocardiograms, chest X-rays, and echocardiography were conducted to rule out any cardiac disease. Those who have tenderness in the costochondral junction in the clinical study were enrolled. Serum vitamin D level was done in all enrolled patients.

Statistical analysis: Statistical Package for the Social Sciences (SPSS) ver. 20 software was used to analyze the data. Quantitative data are expressed as mean and standard deviation, whereas categorical data are expressed as numbers and percentages. Pearson correlation was performed to obtain its coefficient. A pvalue of $<0.05$ is considered significant.

\section{Results:}

A total of 100 patients were studied. In the study patients, $63 \%$ and $37 \%$ were female and male, respectively. Most of the female patients were under the $18-40$ age group $(61.9 \%)$, and male patients were $>40$ age group (54\%). Mean vitamin D level was lower in females as compared to males $(21.9 \pm 8.47$ and $31.7 \pm 6.23$ respectively). Most female patients presented as acute chest pain of short duration $(63.5 \%)$. The frequency of chest pain was more in males as compared to females. [Table 1] According to Pearson Correlation, pain duration was increased with decreasing vitamin $\mathrm{D}$ level that was statistically significant $(\mathrm{p} \leq 0.001)$. [Table 2]

Table 1: Characteristic of the study population

\begin{tabular}{|l|l|l|l|l|}
\hline \multicolumn{2}{|l|}{ Characteristics } & Male & Female & Total \\
\hline \multirow{2}{*}{ Age (years) } & $18-40$ & $17(30.3 \%)$ & $39(69.7 \%)$ & $56(100)$ \\
\cline { 2 - 5 } & $>40$ & $20((45.5 \%)$ & $24(54.5 \%)$ & $44(100)$ \\
\hline $25(\mathrm{OH})$ D level (ng/dl) & $<1$ & $31.7 \pm 6.23$ & $21.9 \pm 8.47$ & \\
\hline \multirow{2}{*}{ Pain duration (months) } & $>1$ & $31(36.47 \%)$ & $54(63.53)$ & $85(100)$ \\
\cline { 2 - 5 } & Single episode / day & $6(40)$ & $9(60)$ & $15(100)$ \\
\cline { 2 - 5 } & $>1 /$ day & $17(60.72)$ & $11(39.28)$ & $28(100)$ \\
\hline \multirow{2}{*}{ Pain frequency } & $45(62.5)$ & $27(37.5)$ & $72(100)$ \\
\hline
\end{tabular}

Table 2: Pearson correlation of vitamin $D$ level with pain duration and its frequency

\begin{tabular}{|l|l|l|}
\hline Parameter & Pearson correlation coefficient & P-value \\
\hline Pain duration & -0.782 & $<0.001$ \\
\hline Pain frequency & 0.377 & 0.211 \\
\hline
\end{tabular}




\section{Discussion:}

In the present study, all patients were clinically and investigation-wise evaluated for cardiac chest pain but eventually diagnosed with costochondritis and vitamin D deficiency. The prevalence of Vitamin D deficiency is reported worldwide, including in developing and developed countries. The majority of vitamin D deficiency cases are undiagnosed and undertreated.[7,8] Previous community-based Indian studies on apparently healthy controls reported a prevalence ranging from $50 \%$ to $94 \% .[9,10]$

There are several reasons for vitamin D deficiency in India, including low dietary intake, Liver, kidney, and skin disorders, increased indoor lifestyle, pollution, and application of sunscreens, cultural practices like burqa and purdah system.

Vitamin D deficiency can cause both skeletal and extraskeletal manifestations. In adults, vitamin $\mathrm{D}$ deficiency leads to low calcium absorption and reduced bone mineral density, resulting in osteoporosis and osteomalacia, and increased fracture frequency. [11,12] Several extra-axial manifestations of vitamin D deficiency, including depression, cancer, Parkinson's disease, increased tendency of suicide, heart disease, low immunity, have been reported. [13-17]

The skeletal manifestation of vitamin D deficiency includes rickets in children and osteomalacia in adults. $[18,19]$ Osteomalacia is usually diagnosed by bony pain with low serum vitamin level $(<25 \mathrm{nmol} / \mathrm{L})$. Sternum and costochondral junction pain has been observed in a milder form of osteomalacia that includes aching, sharp, or pressure-like symptoms and pain increased on upper body movement, on deep inspiration.

A literature review revealed only one casecontrol study conducted on school-aged children [20], and few case reports and observation studies $[21,22]$ on association with non-cardiac chest pain and vitamin D deficiency are available as per our best knowledge.
In the present study, the presentation of costochondritis was more in females; a similar finding was noted in Ghandi Y et al. [20], although later study was limited to children only. The mean value of vitamin $\mathrm{D}$ was low in both males and females. In most female patients, the level of vitamin D was in the severely deficient category $(<20 \mathrm{ng} / \mathrm{ml})$, possibly due to poor nutrition and less exposure to sunlight in females. Patients enrolled in the present study did not have any serious medical condition. Low vitamin D levels were noted in children with costochondritis compared to age-matched controls in Ghandi Y et al .similar finding was seen in Robert $\mathrm{C}$ et al. [21].

In the present study, as per Pearson's correlation test, increased costochondral pain duration was associated with a low level of vitamin $\mathrm{D}$ level that was statistically significant $(p<0.001)$. Torun et al. [23] noted a significant association between vitamin $\mathrm{D}$ deficiency and prolonged duration, increased frequency of non-cardiac chest pain in children. These findings were also supported by Ghandi Y et al. [20]

After analysis of previously available data, and in line with the present study, costochondritis seems associated with vitamin D deficiency, and vitamin $\mathrm{D}$ replacement therapy may alleviate symptoms and improve the quality of life. [24] However, more future studies are required to evaluate the association of costochondritis with vitamin $\mathrm{D}$ deficiency and treatment. There are several limitations in the present study, including single-center, less number of subjects, the cross-sectional design of the study, no follow-up after vitamin D replacement.

\section{Conclusion:}

Vitamin D deficiency should be considered in costochondritis or bony sternal pain. All such individuals should undergo serum $25-\mathrm{OH}$ levels. These patients should be treated with vitamin D replacement along with dietary instruction if they are found deficient. A possible cause for deficiency should also be evaluated to reduce costochondral pain or other manifestations of 
vitamin D deficiency. Further prospective studies are warranted.

\section{References:}

1. S. R. Pitts, R. W. Niska, J. Xu, and C. W. Burt, "National hospital ambulatory medical care survey: 2006 emergency department summary," National Health Statistics Reports, no. 7, pp. 2-39, 2008.

2. M. H. Ebell, "Evaluation of chest pain in primary care patients," American Family Physician, vol. 83, no. 5, pp. 603-605, 2011.

3. A. M. Proulx and T. W. Zryd, "Costochondritis: diagnosis and treatment," American Family Physician, vol. 80, no. 6, pp. 617-620, 2009.

4. Aparna P, Muthathal S, Nongkynrih B, Gupta SK. Vitamin D deficiency in India. J Family Med Prim Care. 2018;7(2):324-330. doi:10.4103/jfmpc.jfmpc_78_18

5. M. Schiltknecht and J. Furrer, "Chest pain in a 37-year-old Sikh," Praxis, vol. 91, no. 4, pp. 99-102, 2002.

6. T. Mosimann and C. Meier, "Left-sided chest pain," Praxis, vol. 92, no. 8, pp. 353355, 2003.

7. van Schoor NM, Lips P. Worldwide Vitamin D status. Best Pract Res Clin Endocrinol Metab 2011;25:671-80.

8. Mithal A, Wahl DA, Bonjour JP, Burckhardt P, Dawson-Hughes B, Eisman JA, et al. Global Vitamin D status and determinants of hypovitaminosis D. Osteoporos Int 2009;20:1807-20

9. Suryanarayana P, Arlappa N, Sai Santhosh V, Balakrishna N, Lakshmi Rajkumar P, Prasad U, et al. Prevalence of Vitamin D deficiency and its associated factors among the urban elderly population in Hyderabad metropolitan city, South India. Ann Hum Biol 2018;45:133-9.

10. Harinarayan CV. Prevalence of Vitamin D insufficiency in postmenopausal South Indian women. Osteoporos Int 2005;16: 397-402.

11. Holick MF, Chen TC. Vitamin D deficiency: A worldwide problem with health consequences. Am J Clin Nutr 2008;87: 1080S-6S.

12. Trivedi DP, Doll R, Khaw KT. Effect of four monthly oral Vitamin D3 (cholecalciferol) supplementation on fractures and mortality in men and women living in the Aparna, et al.: Vitamin D deficiency Journal of Family Medicine and Primary Care 330 Volume 7: Issue 2: March-April 2018 community: Randomised double-blind controlled trial. BMJ 2003;326:469.

13. Nebhinani N, Sharma P, Suthar N. Role of Vitamin D supplementation in patients with depressive disorders and hypovitaminosis D: A longitudinal study. J Ment Health Hum Behav 2017;22:14-20.

14. Lappe JM, Travers-Gustafson D, Davies KM, Recker RR, Heaney RP. Vitamin D and calcium supplementation reduces cancer risk: Results of a randomized trial. Am J Clin Nutr 2007;85:1586-91

15. Butler MW, Burt A, Edwards TL, Zuchner S, Scott WK, Martin ER, et al. Vitamin D receptor gene as a candidate gene for Parkinson disease. Ann Hum Genet 2011;75:201-10.

16. Umhau JC, George DT, Heaney RP, Lewis MD, Ursano RJ, Heilig M, et al. Low Vitamin D status and suicide: A case-control study of active duty military service members. PLoS One 2013;8:e51543.

17. Wang TJ, Pencina MJ, Booth SL, Jacques $\mathrm{PF}$, Ingelsson E, Lanier K, et al. Vitamin D deficiency and risk of cardiovascular disease. Circulation 2008;117:503-11.

18. F. R. Greer and L. Finberg, "Rickets. eMedicine,"

http://emedicine.medscape.com/article/9855 10-overview.

19. M. F. Holick, "Resurrection of vitamin D deficiency and rickets," Journal of Clinical Investigation, vol. 116, no. 8, pp. 20622072, 2006.

20. Ghandi Y, Habibi D, Mohajer O. Assessment of Correlation Between Costochondritis and Vitamin D Insufficiency in School-age Children. J 
Compr Ped.12(3):e102388. doi: 10.5812/ compreped.102388.

21. Robert C. Oh, Jeremy D. Johnson, "Chest Pain and Costochondritis Associated with Vitamin D Deficiency: A Report of Two Cases," Case Reports in Medicine, vol. 2012, Article ID 375730, 3 pages, 2012. https://doi.org/10 $.1155 / 2012 / 375730$

22. Kayali ,S, Belder N, Gökçebay DG. Could there be any relationship between nutritional deficiencies and idiopathic chest pain in children? Eur Res J. 2018;5(3):497-501.
23. Torun E. The relationship between idiopathic chest pain, Vitamin D deficiency, and insufficiency in school children and adolescents. Dicle Med J. 2014;41(1):41-6. doi: 10.5798/diclemedj.0921.2014.01.0370

24. de Torrente de la Jara G, Pecoud A, Favrat B. Female asylum seekers with musculoskeletal pain: the importance of diagnosis and treatment of hypovitaminosis D. BMC Fam Pract. 2006;7:4. doi: 10.1186/1471- 2296-7-4. 